\title{
Applied efficiency analysis in education
}

\author{
Shawna Grosskopf ${ }^{1 *} \cdot$ Kathy J. Hayes $^{2} \bullet{\text { Lori L. } \text { Taylor }^{3}}^{3}$ \\ ${ }^{1}$ Department of Economics, Oregon State University, USA \\ ${ }^{2}$ Department of Economics, Southern Methodist University, USA \\ ${ }^{3}$ Bush School of Government and Public Service, Texas A\&M University, USA
}

\begin{abstract}
Performance in the education sector is of interest in terms of its share of private and public expenditures as well as its key policy relevance through its links to human capital, growth and innovation. Measuring efficiency in services in general and education in particular is challenging. Luckily there are recently developed empirical models - specifically what we call frontier modelswhich can address some of these challenges. Here we focus on some of the modeling and measurement choices that are important for those seeking to apply frontier efficiency methods to the educational arena. Included is a discussion of available data choices for the practitioner.
\end{abstract}

Keywords: frontier efficiency models, nonparametric, stochastic

JEL Classification Codes: H75, I22, I21

\section{Introduction}

Some of the earliest empirical efforts seeking insights into improving performance or efficiency were in educational applications. In part this was because education is a significant sector in terms of public and private expenditures and is of key policy relevance due to its presumed links to human capital, growth and innovation. But it was also partially due to data availability and the development of empirical techniques which addressed some of the difficulties in modeling education. Much of the early work in economics is associated with the education production function literature, which found little consistent evidence for

\footnotetext{
" Corresponding author. E-mail: shawna.grosskopf@orst.edu.

Citation: Grosskopf, S., Hayes, K.J. and Taylor, L.L. (2014) Applied efficiency analysis in education, Economics and Business Letters, 3(1), 19-26.
} 
improving outcomes through increased expenditures on educational 'inputs' -see Hanushek (1986), who suggested that inefficiency may be one reason for these inconclusive results.

Although perhaps not appreciated at the time in the economics literature, Charnes, Cooper and Rhodes (1978, 1981) introduced what they called Data Envelopment Analysis (DEA) which they illustrated with an application to the educational sector, Program Follow Through. This explicitly allowed for multiple outcomes and inputs, and used sample data to construct a best practice frontier relative to which individual 'decision making units' could be evaluated using nonparametric linear programming techniques ${ }^{1}$. Stochastic (parametric) frontier techniques were developed at about the same time as DEA, and were also applied to education-see Worthington (2001) for a review.

Here we focus on some of the modeling and measurement choices that are important for those seeking to apply frontier efficiency methods to the educational arena. Included is a discussion of available data choices for the practitioner.

\section{Models}

There are many economic models that have been brought to bear on the analysis of efficiency in education, most based on functions familiar from production theory. These functions have several features to recommend them for efficiency assessment in this sector -they are naturally defined as maxima or minima, providing frontiers. Most accommodate multiple outputs and inputs. Several can accommodate the equivalent of a budget constraint, whereas others are useful where prices are difficult to measure or uninformative.

Table 1. Some models for education efficiency

\begin{tabular}{l|ccc}
\hline \multicolumn{1}{c|}{ Function } & Definition & Data & Example \\
\hline \hline Production Fn & $f(x)=\max \{y: y \in P(x)\}$ & $y, x$ & Ruggiero (1996) \\
Output Dist Fn & $D_{o}(x, y)=\min \{\theta: y / \theta \in P(x)\}$ & $y, x$ & Färe et al. (2006) \\
Input Dist Fn & $D_{i}(y, x)=\max \{\lambda: x / \lambda \in L(y)\}$ & $y, x$ & Grosskopf et al. (2001) \\
Directional Dist Fn & $\vec{D}_{T}(x, y ; g)=\max \left\{\beta: x-\beta g_{x}, y+\beta g_{y} \in T\right\}$ & $x, y, g_{x}, g_{y}$ & Grosskopf et al. (2013) \\
Cost Fn & $C(y, w)=\min \{w x: x \in L(y)\}$ & $C, w, y$ & Gronberg et al. $(2011)$ \\
Indirect Output Dist Fn & $I D o(w / C, y)=\min \{\theta: y / \theta \in I P(w / C)\}$ & $C, w, y$ & Grosskopf et al. $(1997)$ \\
\hline \hline
\end{tabular}

Table 1 summarizes the functions commonly used in the literature, along with their data requirements and an example of an application. The notation is as follows: $x$ refers to input quantities, generally a vector, $y$ refers to output(s), $w$ and $p$ are their associated prices, respectively. $P(x)$ is the output or production possibilities set, $L(y)$ is the input requirement or upper level set, $T$ is the graph or total product set. These are alternative (equivalent) representations of the primal technology. $I P(w / C)$ is the cost indirect output set which adds a budget constraint to the output set.

The first four functions are based solely on primal quantity data, i.e., they don't require prices. The production function is limited due to the fact that it is defined only for scalar output. This is remedied by the input and output distance functions, which effectively

\footnotetext{
${ }^{1}$ Other developments in the nonparametric approach include Free Disposal Hull Models, and robust, conditional estimators.
} 
generalize to the multiple output case. They also have a direct link to Farrell measures of (radial) technical efficiency as their reciprocals and can be estimated as stochastic or nonparametric frontiers ${ }^{2}$. The directional distance function generalizes the input and output distance functions by simultaneously adjusting inputs and outputs, using the direction vector $g_{x}, g_{y}$ which is chosen by the investigator ${ }^{3}$. One may also use this model to partition the output vector into desirable and undesirable components and simultaneously reduce the 'bads' (such as dropout rates) and increase the goods (test scores, graduation rates, etc.).

The cost function is perhaps the most familiar and widely used of these functions, especially for policy purposes. It identifies cost efficiency and allocative efficiency, the latter through the cost minimizing solution which identifies optimal input quantities ${ }^{4}$. The cost indirect output distance function is closely related to the cost function. However, its objective function is to maximize outputs subject to a budget constraint (which generally is closely related to cost). Here the budget constraint requires that spending can't increase, but inputs may be reallocated to allow increases in outputs. This model mimics the institutional arrangements of many public school systems ${ }^{5}$.

\section{Appropriate output measurement}

As the table illustrates, all of the models demand that the researcher define the outputs of the educational organization. Numbers of pupils, numbers of graduates, passing rates and average test scores have all been used as output measures in educational efficiency analyses ${ }^{6}$. Often the choices are driven by data availability.

None of these measures are ideal, however. The number of pupils may capture the quantity of educational output, but it does not capture the quality. Meanwhile, levels measures of performance (like graduation rates, passing rates or average test scores) are the product not only of the current level of educational inputs, but also of the inputs provided in earlier years at earlier grades and, frequently, at some other school. Gronberg, Jansen and Taylor (2011) argue persuasively that value-added analysis (which measures changes in student performance from one year to the next) yields better output measures for efficiency analysis than does relying on levels measures of performance. As recent analysis by Grosskopf, Hayes and Taylor (2013) demonstrates, efficiency analyses can be very sensitive to the differences between levels and value-added measures of student performance ${ }^{7}$. As economists, we concur with Gronberg et al. (2011) and prefer the value-added measure.

Value-added analysis requires access to panel data on individual students, so that researchers can calculate changes in performance. Commonly available data sources, such as PISA, TIMMS or NAEP, are cross-sectional and cannot be used to generate value-added scores. However, one of the byproducts of the No Child Left Behind Act of 2001 has been the development of panel datasets of student performance in many U.S. states, including Texas, North Carolina and Florida. Such data can and have been used to generate value-added measures for use in educational efficiency models (e.g., Gronberg, Jansen and Taylor, 2012).

\footnotetext{
${ }^{2}$ The distance functions also play a role in the specification of Malmlquist productivity indexes.

${ }^{3}$ It may also be endogenized-see Färe, Grosskopf and Whittaker (2013).

${ }^{4}$ The distance functions can also be used to identify allocative efficiency by estimating shadow prices of the inputs and outputs.

${ }^{5}$ For a generalization of this approach see Blank (2013).

${ }^{6}$ Other outcomes such as post schooling earnings and employment rates are also employed. In higher education the outputs are also typically augmented to include research outputs — see Johnes (2004).

${ }^{7}$ Of course, many educational outputs - such as citizenship are not measurable making even the best specified value-added metric an incomplete output indicator.
} 
Furthermore, five years of high quality estimates of the value added in reading and mathematics by schools and districts in Texas (including charter schools) are available for download from the Financial Allocation Study for Texas (FAST) ${ }^{8}$. The FAST value-added measures were estimated using hierarchical linear modeling and student level data to measure school and district effects holding student demographics constant at the state mean. The FAST output measures also can be easily matched to school and district level data on input prices and quantities.

As pointed out in Gronberg et al. (2012), endogeneity of educational outputs can be a serious econometric issue when estimating cost (or distance) functions. A frequent approach is instrumental variables. In the educational context one needs to find variables that are strongly correlated with output and have no correlation with cost, except through their correlation with output, requirements that are difficult to meet. As discussed in Grosskopf, Hayes and Taylor (forthcoming), researchers have struggled to identify instruments that are correlated with educational outputs but not correlated with unobserved educational inputs.

\section{Discretionary inputs}

Discretionary inputs are those under control of the school, school district or university ${ }^{9}$. In a cost function regression setting, theory dictates that these inputs should be included in terms of input prices, the most important of which are personnel salaries. In a distance or production function setting, whether parametric or nonparametric, discretionary inputs should be specified in terms of input quantities. In practice this distinction is not clear-cut. Expenditure measures have been used as proxies for both prices and quantities of inputs.

Various personnel categories are the most common discretionary inputs. However, specifying either real inputs or wages is difficult given available data, and the obvious variation in teachers and their wages introduces measurement error. Using expenditure as a proxy for real inputs assumes no variation in either prices or quality within each expenditure category. Using average wages of teachers and administrators as input prices face the same issues and also introduce measurement error. In the case of wages, a more precise measure would be a wage index that tells us what the educational institution must pay for a teacher or administrator, for example, with a set of relevant characteristics such as average years of experience and basic educational level. This wage index then can be used to determine equivalent teacher and administrator quantities by dividing the associated expenditures by this index.

\section{Nondiscretionary inputs: environmental characteristics}

Student and parent characteristics as well as peer effects have well-known effects on educational achievement, yet they are typically not under the control of the educational institution. Nevertheless, proxies for these and other environmental variables are widely included in applied educational efficiency studies, with socioeconomic status and parental educational levels perhaps the most common (Worthington, 2001). Other nondiscretionary variables such as location controls as well as proxies for various constraining factors such as institutional structure, degree of monitoring and competition have also been included.

\footnotetext{
${ }^{8}$ www.fastexas.org

${ }^{9}$ Interestingly, this means that input quantities are not exogenous, therefore introducing econometric issues concerning endogeneity. Indeed, the measurement of efficiency under various aspect of endogeneity could be a very fruitful research area.
} 
There are methodological issues which arise in specification of nondiscretionary inputs as well as conceptual issues which also require consideration in empirical applications. Widely employed are so-called two-step or two-stage estimation approaches, most commonly in DEA analyses where the first stage includes only discretionary inputs, and in a second stage the nondiscretionary variables are regressed on the efficiency scores from the first stage. Simar and Wilson (2008) have recommended that if this approach is taken, truncated rather than Tobit regression is appropriate and a bootstrap of those results should be included to address serial correlation issues. More recently, Badin, Daraio and Simar (2012) have proposed a twostage procedure in the context of robust, conditional estimators with second stage nonparametric regression. Others have included the nondiscretionary variables in the first stage in both regression and DEA models.

A conceptual issue arises when the relative efficiency of charter, magnet, and private schools or higher education institutions are compared say to public institutions (for example, see Perelman and Santin, 2011). Because students may choose their schools based on input or output characteristics, there are student selectivity issues which must be addressed: the student population served in these cases is not completely nondiscretionary ${ }^{10}$.

\section{Pros and cons of empirical approaches and specifications}

There are many empirical approaches to measuring efficiency but the education literature for the most part has used nonparametric (DEA, FDH, partial frontiers) and stochastic methods. There are advantages and disadvantages to each (see Grosskopf, Hayes and Taylor (forthcoming)). The nonparametric methods can handle multiple inputs and outputs in a straightforward manner while stochastic approaches require choosing a single dependent variable $^{11}$. In many cases, nonparametric approaches like DEA can accommodate the implicit goals of the various stakeholders, be it administrators, teachers, students or voters.

DEA type approaches do not require any assumptions about functional form or specification of the error term, while stochastic methods must make these assumptions. DEA type approaches assume all deviations from the frontier are due to inefficiency (no error). This means that bounds on estimates cannot easily be determined, statistical significance is not available, and measurement error in the inputs or outputs can skew the results ${ }^{12}$. However, in the stochastic framework, the researcher must choose at least one functional form and specify the error structure.

As discussed in Grosskopf, Hayes and Taylor (2013), DEA analysis can lead to increased data requirements. For example, if a researcher is estimating a cost function, the DEA analysis needs data on input quantities as well as input prices, outputs and costs; the stochastic approach only requires input prices, outputs and cost.

\section{Policy prescriptions in the literature}

Much of the education efficiency literature has examined how policies impact school or school district efficiency. In this section we will review a few of the relatively recent contributions. In the United States, most states have extensive regulations concerning

\footnotetext{
${ }^{10}$ Student self-selection can also complicate the measurement of educational outcomes for schools of choice.

${ }^{11}$ Clearly multiple outputs can still be accommodated in stochastic frontier models either with a cost function or distance function.

${ }^{12}$ Many of these limitations have been addressed by the introduction of data generating processes, bootstrapping and the introduction of conditional robust estimators. See Simar and Wilson (2008) for an overview, as well as Daraio and Simar (2007).
} 
education policy and curriculum. For example, Grosskopf et al. (1999) use the DEA approach to measure potential gains from relaxing these regulations. They conclude that excessive regulation leads to economic rents particularly for teachers. The literature is mixed on the comparative efficiency of charter schools and the more heavily regulated traditional public schools. Grosskopf et al. (2009) find support for larger measures of relative technical efficiency for Texas charter schools; Carpenter and Noller (2010) find exactly the opposite for Minnesota public schools ${ }^{13}$.

Another policy issue is whether the allocation of resources should be decentralized from the school district to the campus. Grosskopf and Moutray (2001), Naper (2010) and Grosskopf et al. (2013) find support for decentralization in terms of increased efficiency.

Economists typically think competition will improve efficiency, and the literature finds some support-more schools, public and private, lead to more economically efficient outcomes. Grosskopf et al. (2001), Kang and Greene (2002), Misra, Grimes and Rogers (2012), Ni (2009), Duncombe (2012) and Millimet and Collier (2008) report at least some evidence of a positive relationship between competition and efficiency. On the other hand, Waldo (2007) and Duncombe et al. (1997) find no support for a positive relationship between efficiency and competition.

Andrews et al. (2002) provide an early review of the literature on economies of size and potential gains from consolidation. As they illustrate, researchers have generally concluded that some school districts would become more efficient by consolidating. Generally, scaleefficient schools have 600 to 1,000 students (depending on grade level) while scale-efficient school districts have between 2,000 and 6,000 students ${ }^{14}$.

\section{Conclusions}

The educational accountability movement is generating the data needed to support increasingly sophisticated analyses of educational efficiency. However, much remains to be done to enable researchers to fully exploit the newly available data. The nature of the educational process means that inputs and outputs will always be measured imprecisely, so the field would benefit from the development of techniques that are less sensitive to outliers and measurement error. Researchers coming out of the economics of education literature are particularly concerned about the potential endogeneity of input and output quantities, so there is considerable interest in developing tools for dealing with endogeneity in its various forms. Policymakers are interested in using efficiency scores to reward and punish schools, school districts and even teachers, so it is crucially important to strengthen existing strategies for generating confidence bands around efficiency scores and cost projections. There is no consensus about the most appropriate strategy for incorporating student characteristics and other environmental factors into efficiency analyses, so research into the role of nondiscretionary inputs could be particularly useful.

One research area that could prove fruitful is the formal modeling of the determinants of inefficiency. As discussed in Taylor (2010), there are a number of possible explanations for inefficiency in the education sector. Inefficiency could arise from a lack of competition in the education market, bureaucrats with objectives other than student performance, rules and regulations that prevent the sector from allocating resources efficiently, successful rentseeking by labor unions or an inability to exploit economies of scale in sparsely populated areas. Because the appropriate policy response to inefficiency can depend on the explanation

\footnotetext{
${ }^{13}$ Gronberg et al. (2012), Crespo-Cebada et al. (2013) and Cherchye et al. (2010) also compare efficiency across school ownership forms. Because of differing data and approaches, these results are not readily comparable.

${ }^{14}$ Results in Gronberg et al. (2013) suggest small gains for districts with enrollments up to 50,000 students.
} 
for that inefficiency, research incorporating the determinants of inefficiency into the modeling could be particularly influential going forward.

\section{References}

Andrews, M., Duncombe, W. and Yinger, J. (2002) Revisiting economies of size in American education: are we any closer to a consensus?, Economics of Education Review, 21(3), 245-262.

Badin, L., Daraio, C. and Simar, L. (2012) How to measure the impact of environmental factors in a nonparametric production model, European Journal of Operational Research, 223(3), 818-833.

Blank, J.L.T. (2013) Maximizing public value for subsidized non-profit firms: a mathematical economic model, Journal of Productivity Analysis, 40, 173-183.

Carpenter, D. and Noller, S. (2010) Measuring charter school efficiency: an early appraisal, Journal of Education Finance, 35(4), 397-415.

Charnes, A., Cooper, W.W. and Rhodes, E. (1978) Measuring the efficiency of decision making units, European Journal of Operational Research, 2(6), 429-444.

Charnes, A., Cooper, W.W. and Rhodes, E. (1981) Evaluating program and managerial efficiency, an application of data envelopment analysis to program follow through, Management Science, 27(6), 668-697.

Cherchye, L., De Witte, K., Ooghe, E. and Nicaise, I. (2010) Efficiency and equity in private and public education: a nonparametric comparison, European Journal of Operational Research, 202(2), 563-573.

Crespo-Cebada, E., Pedraja-Chaparro, F. and Santin, D. (2014) Does school ownership matter? An unbiased efficiency comparison for regions of Spain, Journal of Productivity Analysis, 41(1), 153-172.

Daraio, C. and Simar, L. (2007) Advanced robust and nonparametric methods in efficiency analysis: methodology and applications, Springer.

Duncombe, W. (2012) Estimating the cost of meeting student performance standards in Texas school districts, Manuscript, Exhibit 1142, Fort Bend Independent School District v. Texas Education Agency, D-1-GV-11-002028, Texas 200th Judicial District Court, Travis County (Austin).

Duncombe,W., Miner, J. and Ruggiero, J. (1997) Empirical evaluation of bureaucratic models of inefficiency, Public Choice, 93(1), 1-18.

Färe, R., Førsund,F., Grosskopf, S., Hayes, K. and Heshmati, A. (2006) Measurement of productivity and quality in non-marketable services, Quality Assurance in Education, 14(1), 21-36.

Färe, R., Grosskopf, S. and Whittaker, G. (2013) Directional distance functions: endogenous directions based on exogenous normalization constraint, Journal of Productivity Analysis, 40(3), 267-269.

Gronberg, T., Jansen, D.W., Karakaplan, M.U. and Taylor, L.L. (2013) School district consolidation: a scale-efficiency tradeoff, unpublished manuscript.

Gronberg, T., Jansen, D.W. and Taylor, L.L. (2011) The adequacy of educational cost functions: lessons from Texas, Peabody Journal of Education, 86(1), 3-27.

Gronberg, T., Jansen, D.W. and Taylor, L.L. (2012) The relative efficiency of charter schools: a cost frontier approach, Economics of Education Review, 31(2), 302-317.

Grosskopf, S., Hayes, K.J., Taylor, L.L. and Weber, W.L. (1997) Budget-constrained frontier measures of fiscal equality and efficiency in schooling, Review of Economics and Statistics, 79(1), 116-124. 
Grosskopf, S., Hayes, K.J., Taylor, L.L. and Weber, W.L. (1999) Anticipating the consequences of school reform: a new use of DEA, Management Science, 45(4), 608620.

Grosskopf, S., Hayes, K.J., Taylor, L.L. and Weber, W.L. (2001) On the determinants of school district efficiency: competition and monitoring, Journal of Urban Economics, 49(3), 413-428.

Grosskopf, S., Hayes, K.J. and Taylor, L.L. (2009) The relative efficiency of charter schools, Annals of Public and Cooperative Economics, 80(1), 67-87.

Grosskopf, S., Hayes, K.J., Taylor, L.L. and Weber, W.L. (2013) Centralized or decentralized control of school resources: a network model, Journal of Productivity Analysis, forthcoming.

Grosskopf, S., Hayes, K.J. and Taylor, L.L. (2013) Efficiency in education: research and implications, Applied Economic Perspectives and Policy, forthcoming.

Grosskopf, S. and Moutray, C. (2001) Evaluating performance in Chicago public high schools in the wake of decentralization, Economics of Education Review, 20(1), 1-14.

Hanushek, E.A. (1986) The economics of schooling, production and efficiency in public schools, Journal of Economic Literature, 24, 1141-1177.

Johnes, J. (2004) Efficiency measurement, in Johnes, G. and Johnes, J. (eds.) International Handbook on the Economics of Education, Northampton, MA: Elgar, 613-742.

Kang, B. and Greene, K.V. (2002) The effects of monitoring and competition on public education outputs: a stochastic frontier approach, Public Finance Review, 30(1), 3-26.

Millimet, D.L. and Collier, T. (2008) Efficiency in public schools: does competition matter?, Journal of Econometrics, 145(1-2), 134-157.

Misra, K., Grimes, P.W. and Rogers, K.E. (2012) Does competition improve public school efficiency? A spatial analysis, Economics of Education Review, 31(6), 1177-1190.

$\mathrm{Ni}$, Y. (2009) The impact of charter schools on the efficiency of traditional public schools: evidence from Michigan, Economics of Education Review, 28(5), 571-584.

Ruggiero, J. (1996) Efficiency of education production: an analysis of New York school districts, The Review of Economics and Statistics, 78(3), 499-509.

Simar, L. and Wilson, P.W. (2008) Statistical inference in nonparametric frontier models: recent developments and perspectives, in Fried, H.O., Lovell, C.A.K. and Schmidt S.S. (Eds.) The Measurement of Productive Efficiency and Productivity Growth, New York: Oxford University Press, 421-521.

Taylor, L.L. (2010) Economic approaches to school efficiency, in Peterson, P., Baker, E. and McGaw, B. (Eds.) International Encyclopedia of Education, Volume 2, Oxford: Elsevier, 210-215.

Waldo, S. (2007) Efficiency in Swedish public education: competition and voter monitoring, Education Economics, 15(2), 231-251.

Worthington, A.C. (2001) An empirical survey of frontier efficiency measurement techniques in education, Education Economics, 9(3), 245-268. 